\title{
Screening for comorbid conditions in patients enrolled in the SODA registry: a 2-year observational analysis
}

\author{
Whitney W. Woodmansee ${ }^{1,2} \cdot$ Murray B. Gordon ${ }^{3} \cdot$ Mark E. Molitch $^{4} \cdot$ Adriana G. loachimescu $^{5} \cdot$ Don W. Carver ${ }^{6}$. \\ Beloo Mirakhur ${ }^{7} \cdot$ David Cox $^{7} \cdot$ Roberto Salvatori $^{8}$
}

Received: 1 November 2017 / Accepted: 21 April 2018 / Published online: 16 May 2018

(c) The Author(s) 2018

\begin{abstract}
Purpose This 2-year analysis assessed frequency of comorbidities and comorbidity screening in the Somatuline (lanreotide, LAN) Depot for Acromegaly (SODA) registry.

Methods Patient data collected included pituitary hormone deficiencies, sleep studies, echocardiograms, gallbladder sonographies, colonoscopies, and glycated hemoglobin (HbA1c) levels. Insulin-like growth factor-1 (IGF-1) and growth hormone levels in patients with (DM) and without (non-DM) diabetes mellitus were analyzed.

Results There were 241 patients enrolled. Pituitary hormone deficiencies were reported more frequently at enrollment in male $(56.9 \%)$ vs female patients $(32.0 \% ; p<0.001)$. TSH deficiency was the most common endocrine deficiency $(69.8 \%)$, followed by gonadotropin deficiency (62.3\%). Screening tests reported at enrollment: sleep studies in $29.9 \%$ (79.2\% had sleep apnea), echocardiogram in $46.1 \%$ (46.8\% abnormal), gallbladder sonography in $18.7 \%$ (17.8\% had gallstones), and colonoscopy in $48.1 \%$ (35.3\% had polyps). Follow-up studies were reported less frequently at 1 and 2 years. HbA1c data were reported in $30.8 \%$ and $41.2 \%$ after 1 and 2 years. HbA1c levels were similar at 1 and 2 years of LAN therapy among DM and non-DM patients with available data. Fewer DM vs non-DM patients achieved IGF-1 below upper limit of normal at Month 24 (58.3\% vs $80.6 \%$; $p=0.033)$.

Conclusions Fewer than half of patients in SODA had screening results reported at enrollment for sleep apnea, cardiomyopathy, and colon polyps. Gallbladder imaging was reported in a minority of patients. Lower IGF-1 control rates were observed in DM vs non-DM patients at Month 24. These data suggest a need for better monitoring of comorbidities in US acromegaly patients.
\end{abstract}

Keywords Acromegaly $\cdot$ Comorbidities $\cdot$ Extended-Release $\cdot$ Lanreotide Depot/Autogel $\cdot$ Observational Study $\cdot$ Registry

Whitney W. Woodmansee

whitney.woodmansee@medicine.ufl.edu

1 Division of Endocrinology, Diabetes and Metabolism, University of Florida, 1600 SW Archer Road, Gainesville, FL 32610, USA

2 Division of Endocrinology, Diabetes and Hypertension, Brigham and Women's Hospital/Harvard Medical School, 221 Longwood Avenue, Boston, MA 02115, USA

3 Allegheny Neuroendocrinology Center, Division of Endocrinology, Allegheny General Hospital, 420 E North Ave, Suite 205, Pittsburgh, PA 15212, USA

4 Division of Endocrinology, Metabolism and Molecular Medicine, Northwestern University Feinberg School of Medicine, $645 \mathrm{~N}$. Michigan Avenue, Suite 530, Chicago, IL 60611, USA
5 Department of Medicine, Division of Endocrinology, Metabolism and Lipids, and Department of Neurosurgery, Emory University School of Medicine, 1365 B Clifton Rd, NE, B6209, Atlanta, GA 30322, USA

6 Ipsen Biopharmaceuticals statistician consultant, 106 Allen Road, Basking Ridge, NJ 07920, USA

7 Medical Affairs, Ipsen Biopharmaceuticals, Inc., 106 Allen Road, Basking Ridge, NJ 07920, USA

8 Division of Endocrinology, Diabetes and Metabolism and Pituitary Center, Johns Hopkins University, 1830 East Monument Street \#333, Baltimore, MD 21287, USA 


\section{Introduction}

Although acromegaly is a rare disease (United States [US] incidence was 11 cases per million person-years and prevalence was $\sim 78$ cases per million per year across 2008-2012) [1], the considerable burden of coexisting comorbidities and increased mortality represents a major medical problem [2-9]. Comorbidities significantly increase the odds of hospitalization and pharmacotherapy cost $[10$, 11]. Adequate management of acromegaly, including biochemical control and treatment of its major comorbidities, lowers the risk of mortality to the level of the general population [12-16], and may reduce healthcare utilization and cost associated with comorbidities [10, 11].

The Somatuline ${ }^{\circledast}$ (lanreotide) Depot for Acromegaly (SODA) registry is a post-marketing, multicenter, observational study of patients treated with lanreotide depot (LAN) in academic and private centers in the US (MS319, ClinicalTrials.gov Identifier: NCT00686348). Previous analyses of SODA have assessed the effectiveness, safety, and convenience of LAN in the treatment of acromegaly [17, 18]. Data from a 1-year analysis of the SODA registry showed that hormonal control was achieved independently of drug injection method, and patients found greater convenience with the use of self- or partner-injections [17]. A follow-up 2-year analysis showed that the majority of patients (54.8\%) achieved both IGF-1 concentrations below upper limit of normal $(<\mathrm{ULN})$ and GH levels $\leq 2.5 \mu \mathrm{g} / \mathrm{L}$ [18]. Disease control, defined as $\mathrm{GH}<1.0 \mu \mathrm{g} / \mathrm{L}$, was achieved in $61.4 \%$ of patients. Treatment-emergent adverse events (AEs) were reported in $54.4 \%$ of patients. The AE profile associated with LAN therapy was similar to the known safety profile of LAN and the somatostatin receptor ligands (SRLs).

Retrospective studies still show an $\sim 70 \%$ increase in average standardized mortality rates in acromegaly patients compared with the general population $[14,15]$. Therefore, addressing comorbidities is an important treatment goal. Various acromegaly treatment guidelines recommend evaluating all patients for associated comorbidities such as hypertension, diabetes mellitus (DM), cardiovascular disease, osteoarthritis, and sleep apnea, and include recommendations on managing comorbidities [2-7]. Screening for colon neoplasia, thyroid nodularity, and hypopituitarism is also recommended. For patients receiving SRLs, only those who develop signs and symptoms of gallstone disease should undergo abdominal ultrasound, and thus routine monitoring is not considered necessary [6]. Despite the availability of guidelines, the frequency with which clinicians screen and monitor comorbid conditions outside of controlled clinical trial settings is not well known. Using data from the SODA registry, the objective of this analysis was to summarize the frequency in which patients were assessed for acromegaly comorbidities in the US.

\section{Patients and methods}

\section{Study design and patient population}

Details of the SODA study design and patient population have been published previously [17, 18]. In brief, the patients were eligible for inclusion if they had a clinical diagnosis of acromegaly and either received LAN as their first medical therapy or were transitioned from other somatostatin analogs. The SODA study was conducted in accordance with the International Conference on Harmonisation Good Clinical Practice, current Food and Drug Administration regulations and guidelines, and local ethical and legal requirements. All data collection, transmission, and storage complied with the US Code of Federal Regulations and the Health Insurance Portability and Accountability Act. Signed informed consent was obtained from each patient at study inclusion.

Demographics, clinical characteristics, and comorbidities listed in the patient medical history were collected at enrollment. Patients could be enrolled before or after starting LAN. Pituitary hormonal deficiencies were reported by the investigator using a checkbox format for ACTH, ADH, $\mathrm{TSH}$, and gonadotropin deficiencies. Menstrual cycle and menopausal status were not recorded. Hypopituitarism was defined as a deficiency in $\geq 1$ of the 4 recorded pituitary hormonal deficiencies. Data from optional speciality tests, including sleep study, echocardiogram, gallbladder sonography, and colonoscopy were recorded as obtained during clinic visits at the discretion of the treating physician. Biochemical control [18] was assessed using serum IGF-1 and random serum GH levels (both evaluated mostly at local laboratories). Since serum GH levels at enrollment were not uniformly available, GH control was only assessed at Month 12 (M12) and M24 and only for patients not on pegvisomant. Control of glucose homeostasis was assessed using glycated hemoglobin (HbA1c) levels, when available, at thresholds of $<5.7 \%$ (in reference range), $5.7 \%-6.4 \%$ (pre-DM), and $\geq 6.5 \%$ (DM). Since $\mathrm{HbA1c}$ levels at enrollment were not uniformly available, HbA1c control was assessed at M12 and M24 only. A patient was defined as having diabetes based on medical history, anti-diabetic medication use, and/or $\mathrm{HbA1c}$ level $\geq 6.5 \%$.

\section{Statistical analysis}

Data for this analysis reflect an interim cut-off as of 29 September 2014. Continuous data were analyzed using descriptive statistics (mean, median, and standard deviations). Student's $t$-tests were performed for exploratory purposes. Categorical data were described by frequencies and by chi-square or Fisher's exact test probabilities, also 
performed for exploratory purposes. Probability tests of categorical data are considered to be chi-square unless noted otherwise. A two-sided $p<0.05$ was considered significant. $P$-values were not adjusted for multiple comparisons. The study population included all patients who received a dose of study drug. This was an observational study, and thus the frequency of study visits and assessments occurred at the discretion of the clinician, which resulted in different sets of patients across visits (unpaired) and reflected the availability of reported data.

\section{Results}

As of 29 September 2014, 241 patients were enrolled and included in the 2-year dataset [18]. Sixty-one patients were $<40$ years of age, 124 were 40-60 years of age, and 56 were $>60$ years of age. Acromegaly was caused by pituitary adenoma in $97 \%$ of patients $(233 / 241)$; 8 patients had other causes, including tumor not identified $(n=2)$, tumor secreting GH-releasing hormone $(n=1)$, McCuneAlbright syndrome $(n=1)$, and cause not specified $(n=4)$. The median time since acromegaly diagnosis was 4.3 years (quartile $[\mathrm{Q}] 1=1.71$ years, Q3 =9.25). Additional demographic and clinical characteristics of the 2-year SODA population can be found in the report by Salvatori et al [18].

Patient comorbidities at enrollment are summarized in Table 1. Almost half (48.6\%) of patients at enrollment had cardiovascular comorbidities, with hypertension being most prevalent $(45.2 \%)$. DM was present in $25.3 \%$ of patients at enrollment. Despite the slight predominance of female patients with acromegaly in SODA, one or more pituitary hormone deficiencies were reported more frequently at enrollment in male $(66 / 116,56.9 \%)$ vs female patients $(40 /$ $125,32.0 \% ; p<0.001$ ) (Table 1). Details regarding specific hormone deficiencies were available in 106 patients with hypopituitarism; most had single hormone deficiencies (61/ $106,57.5 \%$ ), while $25.5 \%$ (27/106), 13.2\% (14/106), and $3.8 \%$ (4/106) had 2, 3, and 4 hormone deficiencies, respectively. TSH deficiency was the most common pituitary hormone dysfunction $(69.8 \%, 74 / 106)$. Gonadotropin deficiency was reported in 66 of the patients with hypopituitarism (62.3\%; 66/106): 57 males $(86.4 \%$; 57/66) and 9 $(13.6 \%$; 9/66) females $(p<0.001)$. Of the 125 females in the study, only $9(7.2 \%)$ were reported to have gonadotropin deficiency and of these, 5 were treated with estrogen. The rates of reported gonadotropin deficiency were similar between women above age $50(7 \% ; 5 / 71)$ and below age 50 $(7.4 \% ; 4 / 54)$. Adrenocorticotropic hormone (ACTH) deficiency occurred in 28 patients. Of the 241,5 (2.1\%) patients had diabetes insipidus, and all 5 had previous pituitary surgery.
Data from the optional speciality tests conducted at enrollment and during SODA and assessments of glucose homeostasis during SODA are shown in Fig. 1.

\section{Screening for sleep apnea: sleep study}

At the enrollment visit, $29.9 \%$ of patients (72/241) had a sleep study recorded, with the majority of these showing sleep apnea (Fig. 1a). At M12 and M24, 2.5\% (4/157) and $2.8 \%(3 / 109)$ of patients had a sleep study (new screenings each, not follow-up), respectively, with $100 \%$ showing sleep apnea.

\section{Screening for cardiac abnormalities: echocardiogram}

At enrollment, $46.1 \%$ of patients $(111 / 241)$ had an echocardiogram; nearly one-half of these $(46.8 \%, 52 / 111)$ were abnormal (Fig. 1b). Abnormalities included ventricular hypertrophy/enlargement in $19.8 \%$ (22/111), valve disorders in $10.8 \%(12 / 111)$, diastolic/systolic dysfunction in $6.3 \%$ (7/111), pulmonary hypertension in $2.7 \%$ (3/111), and other/not specified in $7.2 \%$ (8/111). At M12 and M24, echocardiogram was performed in $8.3 \%$ of patients $(13 / 157$ and $9 / 109$, respectively), with 4 and 5 patients having abnormal results, respectively. Two patients had repeat echocardiograms at M12 and M24. Of interest, a total of 39 patients had both an echocardiogram and a polysomnogram at baseline. Of the patients with both studies $(n=39), 19$ had an abnormal echocardiogram at baseline. For these patients with an abnormal echocardiogram, 94.7\% (18/19) had a sleep study showing sleep apnea compared to $11.1 \%$ $(1 / 19)$ without sleep apnea ( $p=0.02$, Fisher's exact test).

\section{Screening for gallbladder stones: gallbladder sonography}

Of the $18.7 \%$ of patients (45/241) who had gallbladder sonography results recorded at enrollment, 60\% (27/45) had abnormal findings (Fig. 1c). Abnormalities included gallstones in $17.8 \%(8 / 45)$ (small in 7 , large in 1), sludge in $24.4 \%(11 / 45)$, and other abnormalities in $33.3 \%(15 / 45)$ of patients. At M12, 3.2\% of patients (5/157) had gallbladder sonography, with 2 patients having abnormal findings (other abnormalities). At M24, 5.5\% of patients (6/109) had gallbladder sonography, with 5 having abnormalities, including 3 patients each with gallstones (small in 2, large in 1) and other abnormalities.

\section{Screening for colon polyps: colonoscopy}

Approximately half $(48.1 \%, 116 / 241)$ of patients had colonoscopy results recorded at enrollment, and the 65 
Table 1 Patient characteristics and comorbidities in acromegaly patients in the SODA study at enrollment

\begin{tabular}{|c|c|c|c|c|}
\hline Characteristic/comorbidity $^{\mathrm{a}}$ & $\begin{array}{l}\text { Male } \\
(n=116)\end{array}$ & $\begin{array}{l}\text { Female } \\
(n=125)\end{array}$ & $\begin{array}{l}\text { All patients } \\
(N=241)\end{array}$ & $p$-value \\
\hline Age, years; mean \pm SD (range) & $\begin{array}{l}47.4 \pm 13.5 \\
(17-77)\end{array}$ & $\begin{array}{l}52.1 \pm 15.0 \\
(13-86)\end{array}$ & $\begin{array}{l}49.8 \pm 14.4 \\
(13-86)\end{array}$ & 0.011 \\
\hline Cardiovascular $^{\mathrm{b}}$ & $53(45.7)$ & $64(51.2)$ & $117(48.6)$ & 0.392 \\
\hline Arterial hypertension & $49(42.2)$ & $60(48.0)$ & $109(45.2)$ & \\
\hline Coronary artery disease & $7(6.0)$ & $7(5.6)$ & $14(5.8)$ & \\
\hline Peripheral edema & $4(3.5)$ & $4(3.2)$ & $8(3.3)$ & \\
\hline Congestive heart failure & $3(2.6)$ & $2(1.6)$ & $5(2.1)$ & \\
\hline Angina pectoris & $3(2.6)$ & $1(0.8)$ & $4(1.7)$ & \\
\hline Arrhythmias & $3(2.6)$ & 0 & $3(1.2)$ & \\
\hline Cardiomyopathy & $3(2.6)$ & $1(0.8)$ & $4(1.7)$ & \\
\hline Myocardial infarction & $1(0.9)$ & $1(0.8)$ & $2(0.9)$ & \\
\hline Hypopituitarism $^{\mathrm{b}}$ & $66(56.9)$ & $40(32.0)$ & $106(44.0)$ & $<0.001$ \\
\hline TSH deficiency & $37(31.9)$ & $37(29.6)$ & $74(30.7)$ & \\
\hline Gonadotropin deficiency & $57(49.1)$ & $9(7.2)$ & $66(27.4)$ & \\
\hline ACTH deficiency & $18(15.5)$ & $10(8.0)$ & $28(11.6)$ & \\
\hline ADH deficiency & $3(2.6)$ & $2(1.6)$ & $5(2.1)$ & \\
\hline Arthralgia/arthritis & $42(36.2)$ & $48(38.4)$ & $90(37.3)$ & 0.725 \\
\hline Lipid abnormalities & $37(31.9)$ & $43(34.4)$ & $80(33.2)$ & 0.680 \\
\hline Diabetes mellitus & $23(19.8)$ & $38(30.4)$ & $61(25.3)$ & 0.059 \\
\hline Carpal tunnel syndrome & $20(17.2)$ & $18(14.4)$ & $38(15.8)$ & 0.545 \\
\hline Malignancies $^{\mathrm{b}}$ & $6(5.2)$ & $20(16.0)$ & $26(10.8)$ & 0.007 \\
\hline Thyroid carcinoma & $1(0.9)$ & $5(4.0)$ & $5(2.1)$ & \\
\hline Breast & 0 & $4(3.2)$ & $4(1.7)$ & \\
\hline $\begin{array}{l}\text { Skin (melanoma, 2; basal cell carcinoma, } 1 \text {; } \\
\text { skin malignancy not specified, 1) }\end{array}$ & $2(1.7)$ & $2(1.6)$ & $4(1.7)$ & \\
\hline $\begin{array}{l}\text { Brain (brain cell glioma, } 1 \text {; glioblastoma, } 1 \text {; } \\
\text { meningioma, 1) }\end{array}$ & 0 & $3(2.4)$ & $3(1.2)$ & \\
\hline Blood (Burkitt lymphoma, 1; lymphoma, 1) & $1(0.9)$ & $1(0.8)$ & $2(0.8)$ & \\
\hline Prostate & $2(1.7)$ & 0 & $2(0.8)$ & \\
\hline Mandibular & $1(0.9)$ & 0 & $1(0.4)$ & \\
\hline Lung & $1(0.9)$ & 0 & $1(0.4)$ & \\
\hline Cervix uteri & 0 & $1(0.8)$ & $1(0.4)$ & \\
\hline Psychosocial $^{\mathrm{b}}$ & $6(5.2)$ & $15(12.0)$ & $21(8.7)$ & 0.060 \\
\hline Depression & $5(4.3)$ & $10(8.0)$ & $15(6.2)$ & \\
\hline Anxiety & $1(0.9)$ & $8(6.4)$ & $9(3.7)$ & \\
\hline Cerebrovascular (stroke) & $4(3.5)$ & $5(4.0)$ & $9(3.7)$ & $1.000^{\mathrm{c}}$ \\
\hline Osteopenia/osteoporosis & $4(3.5)$ & $5(4.0)$ & $9(3.7)$ & $1.000^{\mathrm{c}}$ \\
\hline Kidney stones & $3(2.6)$ & $1(0.8)$ & $4(1.7)$ & $0.354^{\mathrm{c}}$ \\
\hline Pancreatitis & $1(0.9)$ & $2(1.6)$ & $3(1.2)$ & $1.000^{\mathrm{c}}$ \\
\hline
\end{tabular}

Data are given as $n(\%)$ unless otherwise noted; $p$-values for comparisons between male and female patients are determined by chi-square unless otherwise noted

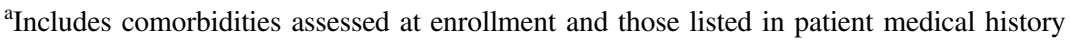

${ }^{b}$ Not mutually exclusive; number of patients with individual comorbidities in a category (bold) may be larger than the number in the overall category. TSH deficiency does not include primary thyroid disease.

${ }^{c} p$-value determined by Fisher's exact test

$A C T H$ adrenocorticotropic hormone, $A D H$ antidiuretic hormone, TSH thyroid-stimulating hormone 
a. Sleep study

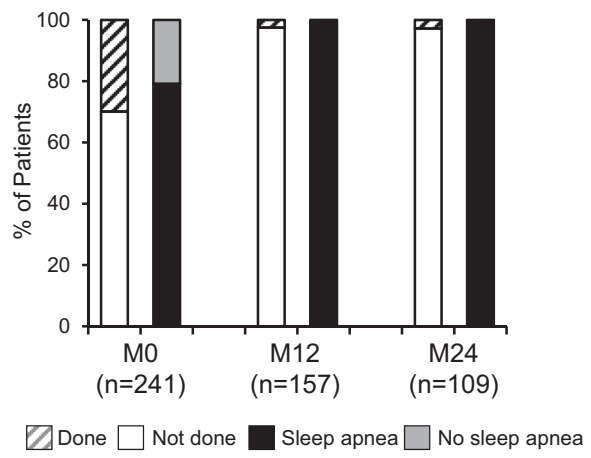

d. Colonoscopy

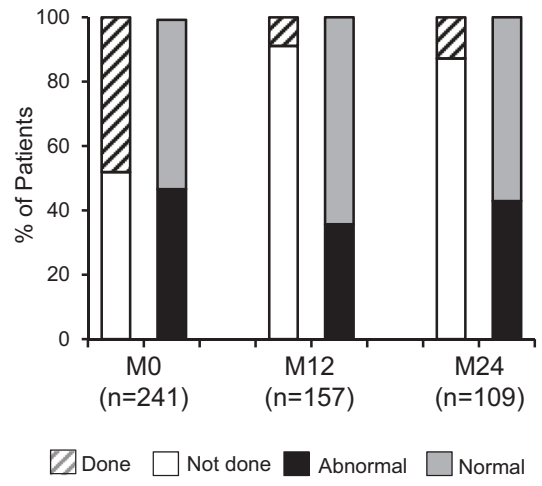

b. Echocardiogram

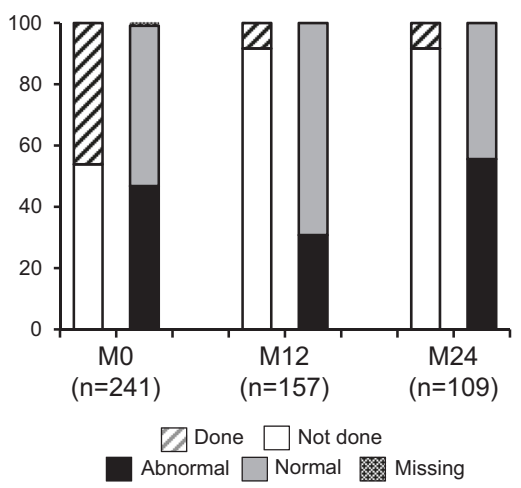

e. $\mathrm{HbA} 1 c^{*}$

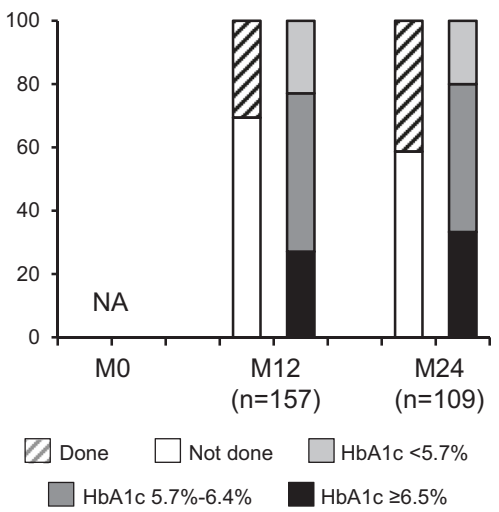

c. Gall bladder sonography

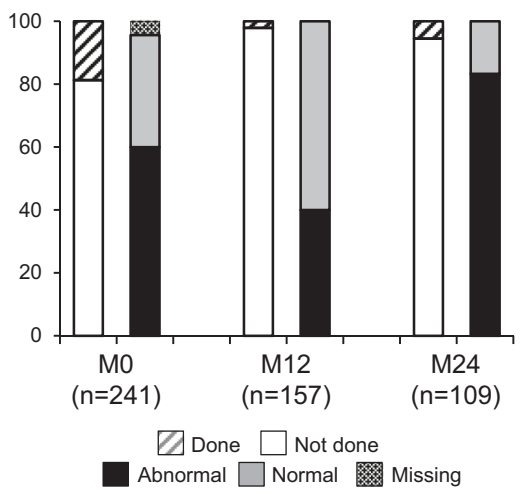

Fig. 1 Optional speciality tests (except $\mathrm{HbA1c}$ ) at enrollment and follow-up assessments in the SODA study. Data in the first bar of each time category include all available patients, and data in the second bar of each category include only those patients who had a test. HbA1c, glycated hemoglobin; M0, Enrollment; M12, Month 12; M24, Month 24; NA, not available. *Total group, includes patients with and without diabetes patients with colonoscopy dates recorded had one within $\sim 3$ years of enrollment. Abnormalities were found in $46.6 \%$ (54/116) (Fig. 1d), including polyps in $35.3 \%$ (41/116) of patients and other abnormalities in $12.1 \%$ (14/116) of patients. At M12, 8.9\% of patients (14/157) had colonoscopy, with 5 patients showing abnormalities, including 3 patients with polyps and 2 patients with other abnormalities. At M24, colonoscopy was performed in $12.8 \%$ (14/109) of patients, with 6 showing abnormalities, including polyps in 6 patients and other abnormalities in 1 patient. No cancers were indicated in any of the abnormal findings.

\section{Glucose homeostasis and biochemical control: diabetes and $\mathrm{HbA} 1 \mathrm{c}$}

HbA1c was measured in $48 / 157$ patients $(30.6 \%)$ at M12 and 45/109 (41.3\%) at M24 (Fig. 1e). DM patients were analyzed for HbA1c in $51.2 \%(22 / 43)$ at M12, and $71.0 \%$ (22/31) at M24, and for non-DM patients in 22.8\% (26/114) at M12, and $29.5 \%$ (23/78) at M24. Mean HbA1c levels among all patients with available data were similar at M12 and M24 within each DM and non-DM group. Within each DM and non-DM group, the proportion of patients with reported $\mathrm{HbA} 1 \mathrm{c}<5.7 \%, 5.7 \%-6.4 \%$, and $\geq 6.5 \%$ at $\mathrm{M} 12$ and M24 were also similar (Fig. 2). A sensitivity analysis was conducted to ascertain the impact of pegvisomant on glucose control in the patients treated with lanreotide. In diabetic patients $(n=22)$, none were receiving pegvisomant, so no comparative analysis was possible. In non-diabetic patients $(n=23)$, only 3 patients were receiving concomitant pegvisomant with $66.7 \%(n=2 / 3)$ reporting a HbA1c between $5.7 \%-6.4 \%$, compared to $65.2 \% \quad(n=15 /$ 23) of those not receiving pegvisomant reporting a HbA1c in the same range. Also within each DM and non-DM group, the proportions of biochemically controlled patients reported within each $\mathrm{HbA} 1 \mathrm{c}$ level at M12 and M24 were similar (Fig. 3).

Biochemical control was reported among the majority of all patients with available data in the DM and non-DM groups at M12 and M24 (Fig. 4). Though the proportion of patients achieving IGF-1 control did not differ between DM and non-DM at enrollment and M12, the study revealed 


\section{a. Diabetes}

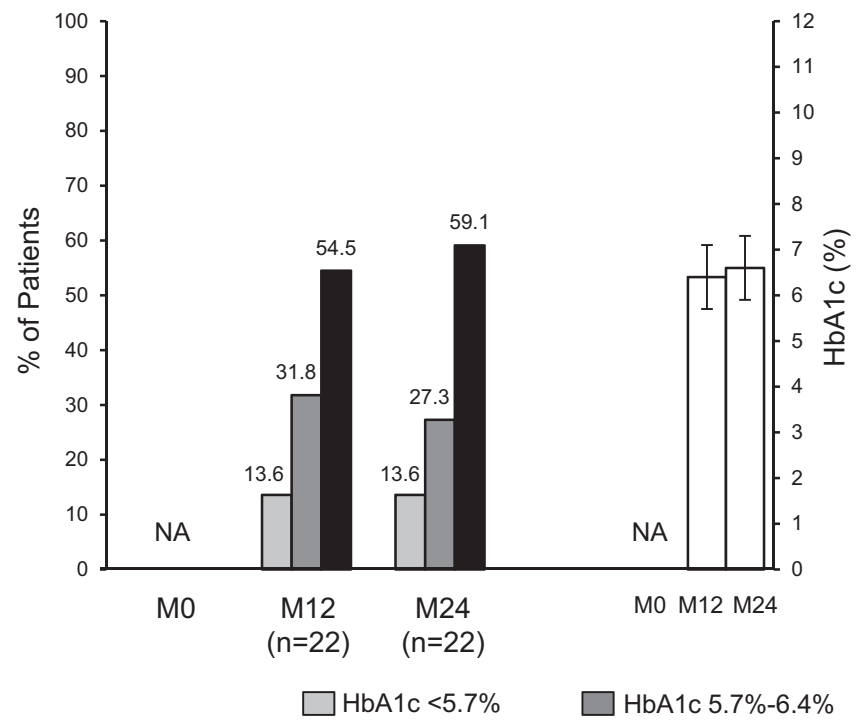

\section{b. No diabetes}

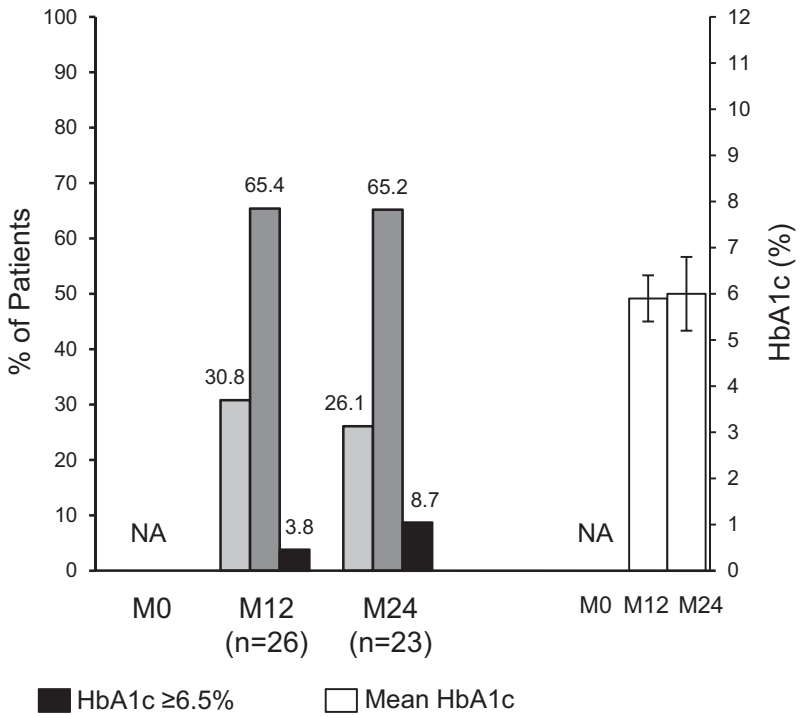

Fig. 2 Proportion of acromegaly patients with (a) and without (b) diabetes in each HbA1c threshold, and mean HbA1c levels (mean \pm standard deviation) in the SODA study. HbA1c, glycated hemoglobin; M0, Enrollment; M12, Month 12; M24, Month 24; NA, not available

\section{a. Diabetes}
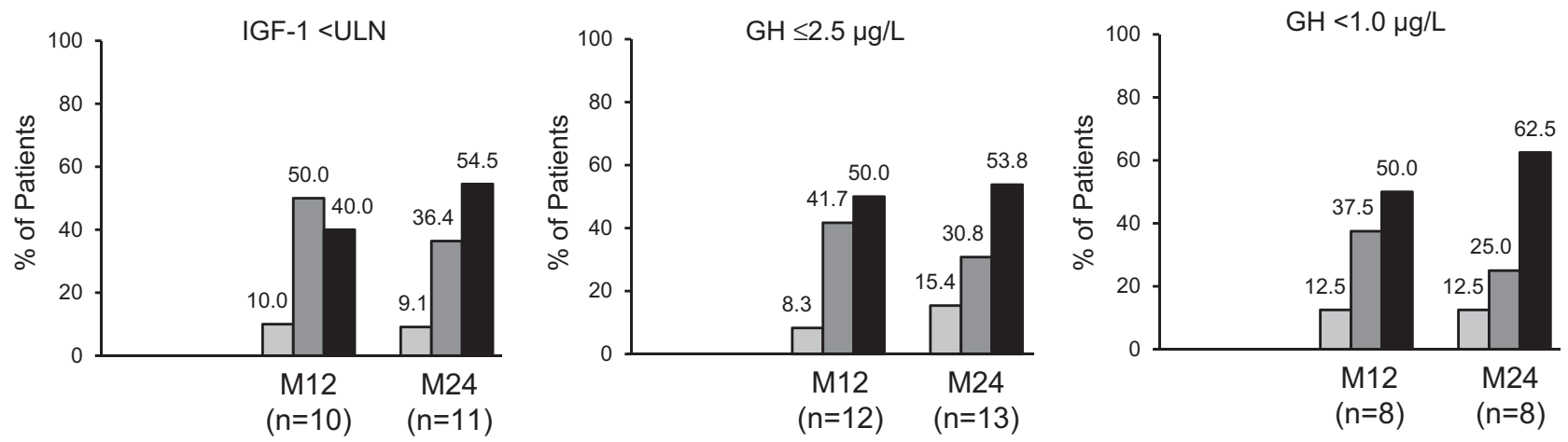

\section{b. No diabetes}
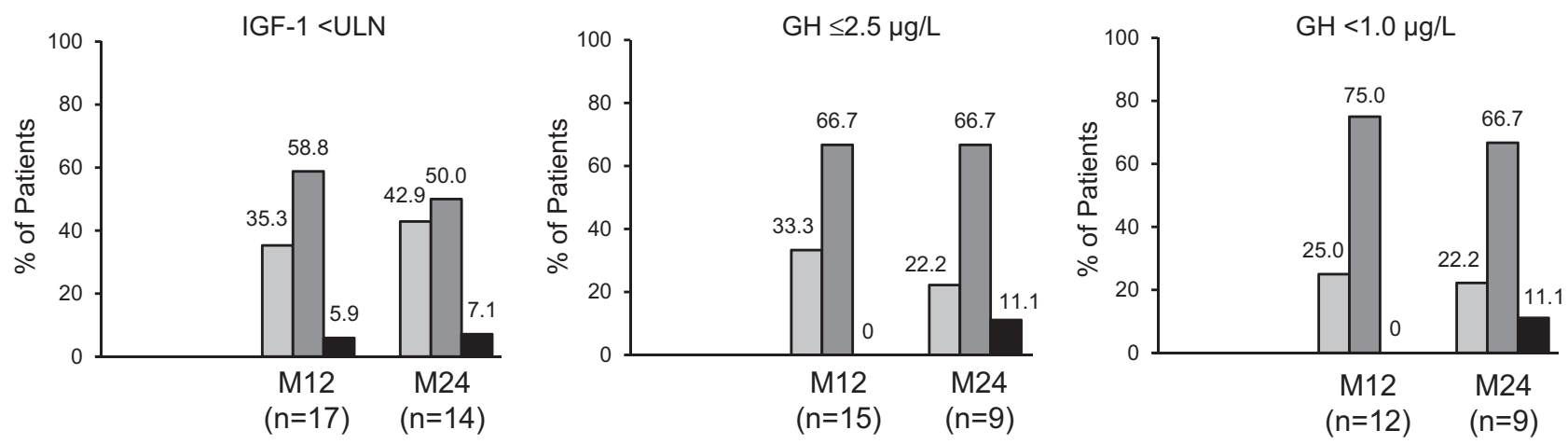

$\mathrm{HbA} 1 \mathrm{c}<5.7 \%$

$\mathrm{HbA} 1 \mathrm{c} 5.7 \%-6.4 \%$

$\mathrm{HbA} 1 \mathrm{c} \geq 6.5 \%$

Fig. 3 Proportion of biochemically controlled acromegaly patients with (a) and without (b) diabetes at each $\mathrm{HbA1c}$ threshold in the SODA study. GH control analyses excluded patients who were taking pegvisomant. GH, growth hormone; HbA1c, glycated hemoglobin; IGF-1 insulin-like growth factor-1, ULN, upper normal level for age and gender; M12, Month 12; M24, Month 24 
a. IGF-1 <ULN

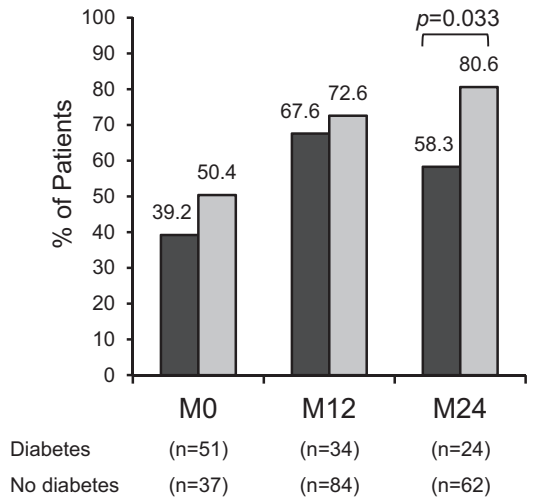

b. GH

$\mathrm{GH} \leq 2.5 \mu \mathrm{g} / \mathrm{L} \quad \mathrm{GH}<1.0 \mu \mathrm{g} / \mathrm{L}$

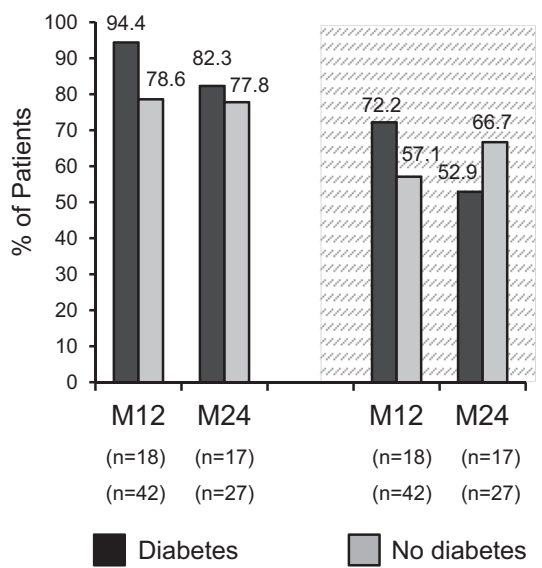

IGF-1 $<\mathrm{ULN} / \quad$ IGF-1 $<\mathrm{ULN}$ $\mathrm{GH} \leq 2.5 \mu \mathrm{g} / \mathrm{L} \quad \mathrm{GH}<1.0 \mu \mathrm{g} / \mathrm{L}$
Fig. 4 Biochemical control in acromegaly patients with and without diabetes in the SODA study. a IGF- $1<\mathrm{ULN}$; b GH $\leq 2.5 \mu \mathrm{g} / \mathrm{L}$, and GH $<1.0 \mu \mathrm{g} / \mathrm{L}$ (gray area); $\mathbf{c}$ Both IGF-1 $<\mathrm{ULN} / \mathrm{GH} \leq 2.5 \mu \mathrm{g} / \mathrm{L}$ and IGF- $1<$ $\mathrm{ULN} / \mathrm{GH}<1.0 \mu \mathrm{g} / \mathrm{L}$. GH control analyses excluded patients who were taking pegvisomant. GH, growth hormone; IGF-1, insulin-like growth factor-1; ULN, upper normal level for age and gender; M0, Enrollment; M12, Month 12; M24, Month 24. Panel 4a appeared as panel 1f and panel $4 \mathrm{~b}$ appeared as panel 3f/4f in Salvatori R, et al (2017) [18]. Used with permission a. Mean LAN Dose

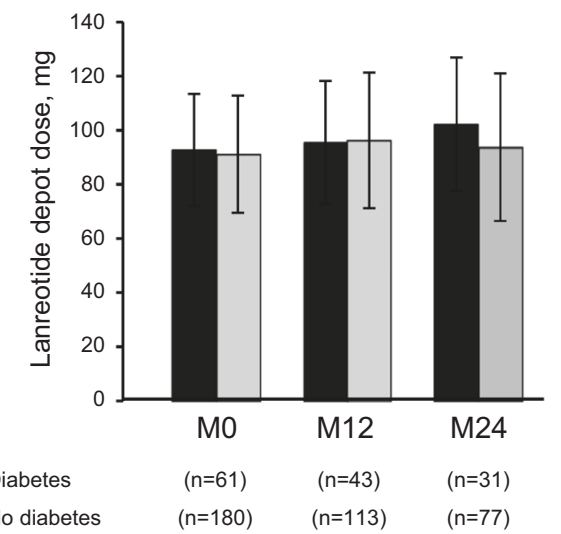

b. LAN $120 \mathrm{mg}$

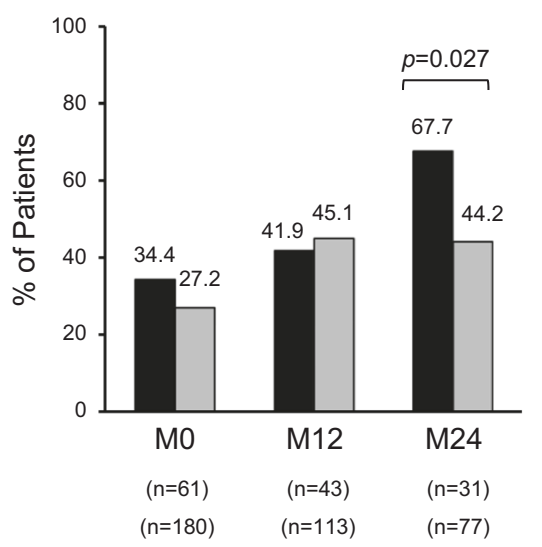

c. Extended dosing interval

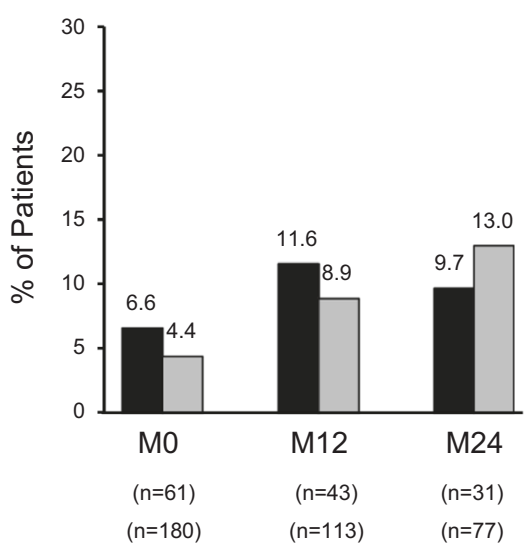

Diabetes

No diabetes

Fig. 5 LAN dose and regimen in acromegaly patients with and without diabetes in the SODA registry: a Mean 28-day dose equivalent (M \pm SD); $\mathbf{b}$ $120 \mathrm{mg}$; c Extended dosing interval. M0, Enrollment; M12, Month 12; M24, Month 24; LAN, lanreotide

lower rates of IGF- $1<\mathrm{ULN}$ in the DM vs non-DM group at M24 $(p=0.033)$.

There were no differences between the DM and non-DM groups in proportion of patients achieving $\mathrm{GH} \leq 2.5 \mu \mathrm{g} / \mathrm{L}$ at M12 and M24, and GH $<1.0 \mu \mathrm{g} / \mathrm{L}$ at M12 and M24 (Fig. 4). Similarly, no differences were revealed in biochemical control of both IGF-1 and GH levels in the DM vs non-DM group.

Mean LAN 28-day dose equivalent use did not differ between the DM and non-DM groups at M12 and M24 (Fig. 5). A greater proportion of DM vs non-DM patients received LAN $120 \mathrm{mg}$ at M24 $(p=0.027)$. Reported LAN extended dosing interval (EDI) use did not differ between the DM and non-DM groups at M12 and M24. There was no significant difference in IGF-1 control between LAN mono- and combination therapy except in non-DM patients at M12, where those receiving LAN monotherapy achieved significantly better IGF-1 control vs combination therapy $(44 / 54,81.5 \%$ vs $17 / 30,56.7 \%$; $p=0.015)$.

\section{Patient deaths}

AEs recorded during the 2-year study period have been reported [18]. Four patients ( 2 male, 2 female) died during 
the 2-year observation ( $n=1$ each, congestive heart failure, heart and respiratory failure, cardiac arrest, and not otherwise specified); all deaths were considered by the investigator to be unrelated to treatment. Comorbidities among these 4 patients included diabetes in 1 , hypertension in 4 , and hyperlipidemia in 2. None of the patients had ACTH deficiency.

\section{Discussion}

In keeping with guidelines and consensus statements on the diagnosis and treatment of acromegaly-associated comorbidities [2, 6, 7], this report examined the frequency of monitoring for comorbidities and described the findings in a cohort of patients with acromegaly from the SODA registry. The frequency of optional testing and comorbidity screening recorded at enrollment, 1, or 2 years was low overall, potentially reflecting the ongoing challenges and geographic differences in managing this population of patients. Approximately $50 \%$ or fewer of patients had results from sleep studies, echocardiograms, gallbladder sonographies, or colonoscopies during study enrollment, and overall follow-up was infrequently reported during the 2-year observation period despite abnormal test results in some patients at enrollment. The reasons for the low frequency of testing for comorbidities are not exactly clear, but may involve differences in assessment practices for patients with a history of acromegaly vs patients at the time of initial diagnosis. Also, practitioners may not be performing certain follow-up assessments if a patient with a history of acromegaly does not also have a history of the comorbid condition. Furthermore, if a patient achieves and sustains target biochemical treatment goals, they may not be perceived of as being at an increased risk for some of the associated comorbid conditions, even though evidence has shown that some potentially severe comorbidities, including arthropathy and sleep apnea, may persist even after long-term biochemical control of acromegaly [19, 20]. Approximately two-thirds of the patients enrolled in the SODA study were recruited from sites in academic medical centers and onethird were from community private practices [17]. However, whether the number of recruited patients per study site was proportional to the volume of acromegalic patients cared for at a particular location is not known. Therefore, no conclusions can be made regarding the frequency of testing for comorbidities and the volume of acromegalic patients seen in a particular center. Limitations attributed to the observational study design may have also contributed to the low frequencies of testing reported. Specifically, patients may have had a particular study performed but the result was either unknown or not recorded in the SODA database by the investigator. In addition, the timeframe of the SODA study should be considered, as the study used a data cut-off of 2014, which was prior to the publication of the most recent acromegaly management guidelines. It should be noted, however, that the incidence of comorbidities was similar and in line with that seen in other observational studies of patients with acromegaly [21, 22].

Cardiovascular comorbidities, including hypertension (predominantly diastolic), left ventricular hypertrophy $(\mathrm{LVH})$, diastolic and systolic dysfunction, arrhythmias, myocardial infarction, enlarged great vessel diameters, and valve diseases are highly prevalent in acromegaly and are considered a major cause of mortality [12, 14-16, 23-27]. Among them, hypertension [16] and cardiomyopathy [24] are considered the main cardiac risk factors that directly impact mortality. Three of 4 deaths in SODA resulted from cardiovascular complications, and all 4 patients had hypertension. Hypertension in SODA was documented in almost half $(45.2 \%)$ of patients at enrollment, consistent with $47.5 \%$ in the US acromegaly registry reported by the Pituitary Center at Cedars-Sinai Medical Center (CSMCPC) [28] but higher than rates documented in other studies, including registry studies (rates ranging from $22 \%$ to $41.3 \%)[9,14,21-24,29,30]$

The prevalence of different features of cardiomyopathy is 3.3-14.2 times higher in the acromegalic than nonacromegalic population, with the disease duration as its major determinant $[24,31]$. Guidelines recommend routine echocardiogram and electrocardiogram at diagnosis and annually during follow-up, especially in patients who have evidence of ventricular hypertrophy by electrocardiography or who are symptomatic, particularly if older $[2,6]$. In SODA, only $3(1.2 \%)$ patients had documented cardiomyopathy at enrollment based on patient medical histories. Taking into account 4.3 years as the median time since acromegaly diagnosis, we can assume that cardiomyopathy was under-assessed in this cohort of patients. Indeed, just under half of the patients had an echocardiogram at enrollment, and very few patients had one at follow-up visits $(<10 \%)$, of whom nearly half had abnormal findings. These data suggest that, in real-world practice, guideline recommendations are not always followed. However, according to the Endocrine Society 2014 Acromegaly Guidelines, the role of pretreatment echocardiogram has not been defined; rather, thorough cardiac evaluation may be indicated by suggestive clinical findings, particularly in perioperative patients [6]. Also, according to a cardiac MRI study, patients with active acromegaly might have a lower (5\%) prevalence of $\mathrm{LVH}$ than previously reported using echocardiogram [32].

Sleep apnea, primarily obstructive, is a frequent comorbidity in acromegaly due to soft tissue thickening and edema of the tongue, pharynx, and upper airways, with a reported prevalence of $25 \%-60 \%$ [5] and $~ 69 \%$ [6]. 
Although biochemical control of acromegaly usually improves sleep apnea, it has been shown to persist in $\sim 40 \%$ of biochemically controlled patients [6, 33]. Guidelines recommend an annual Epworth Sleepiness Scale or sleep study during follow-up of acromegaly [2-4, 6]. Less than one-third of patients had completed a sleep study at SODA enrollment, and very few $(<3 \%)$ had entered a sleep study at follow-up visits. At enrollment, the majority of tested patients had sleep apnea (79.2\%), consistent with other reports [33-35], although the CSMC-PC and ACROSTUDY reported significantly lower $(22.5 \%$ and $17 \%$, respectively) prevalence of sleep apnea [22, 28]. However, these numbers are not strictly comparable, since symptomatic patients were more likely to get sleep studies, and thus the true prevalence may not be reflected. Also, the SODA database did not distinguish between obstructive or central sleep apnea. Nonetheless, given that sleep apnea is independently associated with hypertension and cardiovascular disease $[33,34]$ and proposed to account for up to $25 \%$ of the excess mortality in untreated acromegaly [33], there may be potential for improved outcomes in acromegaly patients if sleep apnea screening is increased.

The frequent prevalence of DM in SODA patients $(25.3 \%)$, along with older-age, higher-BMI, and higher coexistence of hypertension and statin use in DM vs nonDM patients noted in the previous 2-year SODA analysis [18], were findings similar to those reported in several other studies [6, 9, 22] and registries [21, 28, 29, 36]. Hyperglycemia at diagnosis and ongoing SRL treatment are independent predictive factors of persistent or new glucose abnormalities during follow-up [37]. In addition, patients with comorbid DM are reported to have a lower survival rate than patients without DM [38]. Therefore, all patients with acromegaly should be tested for glucose intolerance and DM, appropriately treated, and followed up as indicated for these conditions. Guidelines recommend an oral glucose tolerance test at diagnosis, fasting blood glucose every 6 months (particularly in uncontrolled disease and during SRL therapy), and HbA1c every 6 months if diabetes is present $[2-4,6]$. In SODA, less than half of patients had HbA1c results reported after 1 and 2 years of LAN therapy.

Lowering GH levels improves glycemic control and increases insulin sensitivity in acromegaly; however, SRL therapy may exert variable effects on glucose metabolism, with worsening due to inhibition of insulin secretion and improvement due to improved insulin sensitivity with acromegaly control [39, 40]. Although the number of patients with reported $\mathrm{HbA} 1 \mathrm{c}$ levels in this SODA analysis were small, similar proportions of patients were reported in each HbA1c level at M12 and M24 within each DM and non-DM subgroup. These findings support other reports of the relatively minor impact of SRLs on glucose homeostasis
[39], in particular LAN [41, 42], which is less detrimental to diabetes than the next-generation SRL pasireotide [43].

Reported biochemical control rates were similar among patients at M12 and M24, independent of glucose homeostasis levels. No significant differences between DM and non-DM groups were observed in patients who achieved both $\leq 2.5 \mu \mathrm{g} / \mathrm{L}$ and $<1.0 \mu \mathrm{g} / \mathrm{L} \mathrm{GH}$ control after 1 and 2 years of treatment. Conversely, the data revealed higher rates of IGF-1 <ULN in non-DM vs DM patients after 2 years of treatment. The similar mean LAN 28-day dose equivalent and LAN EDI use, and higher use of the 120-mg LAN dose among DM vs non-DM patients, suggests that inadequate LAN dosing would not account for the higher IGF-1 levels in the DM group at M24. One likely explanation is the hyperinsulinism in the DM group, which enhanced synthesis of IGF-1 through upregulation of hepatic $\mathrm{GH}$ receptors $[17,44,45]$. The disconnect between the similar GH levels in DM vs non-DM patients and the difference in IGF-1 may also be explained by the effect of obesity [45] and hyperinsulinism both increasing hepatic GH sensitivity [46] and increasing free fatty acids, which suppress GH release [47]. These findings are in agreement with another recent analysis of SODA data, which indicated that more obese vs nonobese patients achieved $\mathrm{GH}<1.0 \mu \mathrm{g} / \mathrm{L}$ after both 1 and 2 years of LAN treatment [18]. Notably, this trend of $\mathrm{GH}$ control was opposite to IGF-1 control. These data are in line with those of Matta et al [48], who report metabolic syndrome markers such as higher fasting blood glucose and systolic blood pressure, in treated patients with acromegaly with a high IGF-1 and $\mathrm{GH}<1 \mu \mathrm{g} / \mathrm{L}$.

In some studies, colon polyps and/or cancer have been reported to occur more frequently in acromegaly than in the general population, although data from other studies have not supported this association [49, 50]. There is general agreement, however, that early colonoscopy screening and regular surveillance is justified [38, 49, 51-54]. The Screening Guidelines for Colorectal Cancer and Polyps in Acromegaly [52] recommend regular colonoscopic screening, starting at 40 years of age, with frequency of repeat colonoscopy depending on findings at original screening and acromegaly activity. Almost half of SODA patients had undergone a colonoscopy by enrollment, many within 3 years, and $35.3 \%$ had polyps. These findings are higher than in other studies $[9,10,55]$ and in the Belgian (27.2\%) [21] and CSMC-PC (20.0\%, polyps or colon cancer) [28] registries. Follow-up colonoscopies were recorded in fewer numbers of SODA patients.

Although the impact of acromegaly and its control on neoplasia risk and mortality are controversial [6, 8, 27], the presence of cancer and the last IGF-1 level are considered significant mortality predictors in acromegaly [9, 12, 38]. Malignancies of various systems were reported in $10.8 \%$ of SODA patients at enrollment, which is consistent with 
$10.5 \%$ in the Belgian registry [21]. Thyroid cancer is a commonly reported cancer in acromegaly[6, 9], followed by breast, lung, ovarian, and lymphoma [9]. Consistent with these reports, thyroid, skin, and breast were the most common cancer types in the SODA cohort, followed by brain, blood (lymphoma), and prostate.

Hypopituitarism in acromegaly may develop due to tumor compression or as a result of surgical or radiation treatment. Acromegaly guidelines recommend assessing for hypopituitarism and adequate replacement of adrenal, gonadal, and thyroid insufficiency; patients who receive radiotherapy need lifelong monitoring of pituitary function $[2,4,6]$. In SODA, $44.0 \%$ of enrolled patients presented with pituitary hormone deficiencies, which is higher than the rates reported in several European registries [21, 30, 56]. Similar to the German registry [56], pituitary insufficiency was more commonly reported in males compared to females. The prevalences of TSH and gonadotropin deficiencies were higher in SODA than in the German registry [56], CSMC-PC registry [28], and ACROSTUDY [22]. Interestingly, as in the German registry [56], gonadotropin deficiency in SODA was more commonly reported in males (49.1\%) vs females (7.2\%). The cause for this apparent gender difference is unknown but it is important to consider in registry studies that it may be due to ascertainment bias or potentially less rigorous documentation of gonadal status in women. This gender difference does not appear to be related to tumor size, surgery, or radiation exposure as there were no gender differences noted for these variables in SODA [18]. ACTH deficiency in SODA (11.6\%) was similar to the German registry $(11.8 \%$ ) [56], but lower than in the CSMC-PC registry (14.9\%) [28] and ACROSTUDY (15\%) [22]. ACTH deficiency can lead to adrenal crisis during acute illness and may cause adverse metabolic effects due to chronic supra-physiological glucocorticoid replacement, which are associated with increased mortality in patients with acromegaly [2, 27, 56, 57]. None of the 4 patients who died in SODA had ACTH deficiency.

Gallbladder stones were present in $17.8 \%$ of SODA patients with a gallbladder sonography performed at enrollment, which falls between the rates reported in the ACROSTUDY (7\%) [22] and Belgian registry (23.4\%) [21]. Of note, gallbladder sonography was performed in only $18.7 \%$ of SODA patients. The Endocrine Society guideline does not suggest routine abdominal ultrasound to monitor for gallstone disease in a patient receiving an SRL [6]; however, ultrasound should be performed if a patient has signs and symptoms of gallstone disease. In SODA, the frequency of gallbladder ultrasound was relatively low throughout the observation period, which could be in part because the study protocol excluded patients with symptomatic, untreated biliary lithiasis. Moreover, a retrospective case cohort study of 31 consecutive newly diagnosed patients with acromegaly revealed a significantly increased prevalence of gallbladder polyps compared with a control group [58].

Given that SODA is an observational study, heterogeneity of data collection across centers is an inherent limitation, in addition to the fact that patients in SODA were enrolled at different stages of disease and treatment. Followup in observational studies is generally not as active or as standardized as in randomized trials; therefore, ascertainment of outcomes may be incomplete or inaccurate. The optional studies recorded in the database may not represent a completely accurate account of all the studies actually performed due to the possibility of under-reporting. Although registries are typically more generalizable to 'real world' practice because of their observational design, entry into a registry may not be as strictly monitored compared with randomized trials. This may weaken the generalizability of findings obtained from analysis of registry data. The subgroup comparisons were also limited by small sample sizes in some instances.

In conclusion, this analysis of acromegaly patients from the observational SODA registry found less frequent reallife monitoring of comorbid conditions than recommended by recent treatment guidelines. Additional prospective analysis will be needed to further identify and address potential barriers to managing acromegaly-associated comorbidities and the impact of screening on survival.

Acknowledgements The authors would like to thank the patients and investigators of each participating center in this study. The authors also thank Olga V. Gambetti, MD, PhD, formerly of Ipsen Biopharmaceuticals, Inc, for her assistance with this study and Kathleen Allen, study manager. Sarah Mizne, PharmD, and Michelle Jones, PhD, of MedVal Scientific Information Services, LLC, and Nicole Coolbaugh, BSc, and Philip Sjostedt, BPharm, of The Medicine Group, LLC provided medical writing and editorial assistance, which was funded by Ipsen Biopharmaceuticals, Inc. This manuscript was prepared according to the International Society for Medical Publication Professionals' 'Good Publication Practice for Communicating CompanySponsored Medical Research: The GPP3 Guidelines.'

Author contributions All authors contributed equally and each was involved in study design, data acquisition, or data analysis/interpretation and in drafting or critically revising the manuscript. All authors reviewed the final manuscript and gave approval for submission.

Funding This study was funded by Ipsen Biopharmaceuticals, Inc.

\section{Compliance with ethical standards}

Conflict of interest WWW: Clinical trial investigator: Ipsen, Versartis; Advisor/consultant: Ipsen. MBG: Research support: Chiasma, Corcept, Ipsen, Novartis, Novo Nordisk, Pfizer, OPKO, Strongbridge, Teva. MEM: Research support: Bayer, Ipsen, Johnson \& Johnson, Novartis, Novo Nordisk, Prolor; Advisor/consultant: Corcept, Ipsen, Merck, Novartis, Novo Nordisk, Pfizer. AGI: Research support: Chiasma, Ipsen, Novartis, Pfizer; Advisor/consultant: Chiasma, Ionis, 
Ipsen, Pfizer. DWC: Ipsen consultant. BM, DC: Full-time employees: Ipsen Biopharmaceuticals, Inc. RS: Research support: Chiasma, Novartis, Novo Nordisk, Pfizer, Prolor, Strongbridge; Advisor/consultant: Pfizer.

Ethical approval The SODA study was conducted in accordance with the International Conference on Harmonization Good Clinical Practice Guidelines, current Food and Drug Administration regulations and guidelines, local ethical and legal requirements, and the United States Code of Federal Regulations and the Health Insurance Portability and Accountability Act for the collection, transmission, and storage of study data. All procedures performed involving human participants were in accordance with the ethical standards of the institutional and/or national research committee and with the 1964 Helsinki declaration and its later amendments or comparable ethical standards.

Informed consent Signed informed consent was obtained from each patient at study inclusion.

Open Access This article is distributed under the terms of the Creative Commons Attribution 4.0 International License (http://crea tivecommons.org/licenses/by/4.0/), which permits unrestricted use, distribution, and reproduction in any medium, provided you give appropriate credit to the original author(s) and the source, provide a link to the Creative Commons license, and indicate if changes were made.

\section{References}

1. T. Burton, E. Le Nestour, M. Neary, W.H. Ludlam, Incidence and prevalence of acromegaly in a large US health plan database. Pituitary 19(3), 262-267 (2016). https://doi.org/10.1007/s11102015-0701-2

2. S. Melmed, F.F. Casanueva, A. Klibanski, M.D. Bronstein, P. Chanson, S.W. Lamberts, C.J. Strasburger, J.A. Wass, A. Giustina, A consensus on the diagnosis and treatment of acromegaly complications. Pituitary 16(3), 294-302 (2013). https://doi.org/10. 1007/s11102-012-0420-x

3. S. Melmed, A. Colao, A. Barkan, M. Molitch, A.B. Grossman, D. Kleinberg, D. Clemmons, P. Chanson, E. Laws, J. Schlechte, M.L. Vance, K. Ho, A. Giustina, Guidelines for acromegaly management: an update. J. Clin. Endocrinol. Metab. 94(5), 1509-1517 (2009). https://doi.org/10.1210/jc.2008-2421

4. L. Katznelson, J.L. Atkinson, D.M. Cook, S.Z. Ezzat, A.H. Hamrahian, K.K. Miller, American Association of Clinical Endocrinologists medical guidelines for clinical practice for the diagnosis and treatment of acromegaly-2011 update. Endocr. Pract. 17, 1-44 (2011).

5. A. Giustina, P. Chanson, M.D. Bronstein, A. Klibanski, S. Lamberts, F.F. Casanueva, P. Trainer, E. Ghigo, K. Ho, S. Melmed, A consensus on criteria for cure of acromegaly. J. Clin. Endocrinol. Metab. 95(7), 3141-3148 (2010). https://doi.org/10.1210/jc.20092670

6. L. Katznelson, E.R. Laws Jr., S. Melmed, M.E. Molitch, M.H. Murad, A. Utz, J.A.H. Wass, Acromegaly: an Endocrine Society clinical practice guideline. J. Clin. Endocrinol. Metab. 99(11), 3933-3951 (2014). https://doi.org/10.1210/jc.2014-2700

7. A. Giustina, P. Chanson, D. Kleinberg, M.D. Bronstein, D.R. Clemmons, A. Klibanski, A.J. van der Lely, C.J. Strasburger, S. W. Lamberts, K.K. Ho, F.F. Casanueva, S. Melmed, Expert consensus document: a consensus on the medical treatment of acromegaly. Nat. Rev. Endocrinol. 10(4), 243-248 (2014). https:// doi.org/10.1038/nrendo.2014.21
8. M. Sherlock, J. Ayuk, J.W. Tomlinson, A.A. Toogood, A. Aragon-Alonso, M.C. Sheppard, A.S. Bates, P.M. Stewart, Mortality in patients with pituitary disease. Endocr. Rev. 31(3), 301-342 (2010). https://doi.org/10.1210/er.2009-0033

9. M. Mercado, B. Gonzalez, G. Vargas, C. Ramirez, A.L. de los Monteros, E. Sosa, P. Jervis, P. Roldan, V. Mendoza, B. LopezFelix, G. Guinto, Successful mortality reduction and control of comorbidities in patients with acromegaly followed at a highly specialized multidisciplinary clinic. J. Clin. Endocrinol. Metab. 99 (12), 4438-4446 (2014). https://doi.org/10.1210/jc.2014-2670

10. M.S. Broder, M.P. Neary, E. Chang, D. Cherepanov, L. Katznelson, Treatments, complications, and healthcare utilization associated with acromegaly: a study in two large United States databases. Pituitary 17(4), 333-341 (2014). https://doi.org/10. 1007/s11102-013-0506-0

11. H. Placzek, Y. Xu, Y. Mu, S.M. Begelman, M. Fisher, Clinical and economic burden of commercially insured patients with acromegaly in the United States: a retrospective analysis. J. Manag. Care Spec. Pharm. 21(12), 1106-1112 (2015)

12. F. Bogazzi, A. Colao, G. Rossi, M. Lombardi, C. Urbani, C. Sardella, A. Iannelli, I. Scattina, L. Manetti, S. Del Sarto, R. Pivonello, L.F.S. Grasso, I. Lupi, R.S. Auriemma, G. Lombardi, E. Martino, Comparison of the effects of primary somatostatin analogue therapy and pituitary adenomectomy on survival in patients with acromegaly: a retrospective cohort study. Eur. J. Endocrinol. 169(3), 367-376 (2013). https://doi.org/10.1530/eje13-0166

13. L. Varadhan, R.C. Reulen, M. Brown, R.N. Clayton, The role of cumulative growth hormone exposure in determining mortality and morbidity in acromegaly: a single centre study. Pituitary $\mathbf{1 9}$ (3), 251-261 (2016). https://doi.org/10.1007/s11102-015-0700-3

14. N.R. Biermasz, A.M. Pereira, J.W. Smit, J.A. Romijn, F. Roelfsema, Morbidity after long-term remission for acromegaly: persisting joint-related complaints cause reduced quality of life. J. Clin. Endocrinol. Metab. 90(5), 2731-2739 (2005). https://doi. org/10.1210/jc.2004-2297

15. O.M. Dekkers, N.R. Biermasz, A.M. Pereira, J.A. Romijn, J.P. Vandenbroucke, Mortality in acromegaly: a meta analysis. J. Clin. Endocrinol. Metab. 93(1), 61-67 (2008). https://doi.org/10.1210/ jc. 2007-1191

16. I.M. Holdaway, M.J. Bolland, G.D. Gamble, A meta-analysis of the effect of lowering serum levels of GH and IGF-I on mortality in acromegaly. Eur. J. Endocrinol. 159(2), 89-95 (2008). https:// doi.org/10.1530/eje-08-0267

17. R. Salvatori, W.W. Woodmansee, M. Molitch, M.B. Gordon, K. G. Lomax, Lanreotide extended-release aqueous-gel formulation, injected by patient, partner or healthcare provider in patients with acromegaly in the United States: 1-year data from the SODA registry. Pituitary 17(1), 13-21 (2014). https://doi.org/10.1007/ s11102-012-0460-2

18. R. Salvatori, M.B. Gordon, W.W. Woodmansee, A.G. Ioachimescu, D.W. Carver, B. Mirakhur, D. Cox, M.E. Molitch, A multicenter, observational study of lanreotide depot/autogel (LAN) in patients with acromegaly in the United States: 2-year experience from the SODA registry. Pituitary 20(6), 605-618 (2017). https://doi.org/10.1007/s11102-017-0821-y

19. K.M.J.A. Claessen, S.R. Ramautar, A.M. Pereira, J.W.A. Smit, F. Roelfsema, J.A. Romijn, H.M. Kroon, M. Kloppenburg, N.R. Biermasz, Progression of acromegalic arthropathy despite longterm biochemical control: a prospective, radiological study. Eur. J. Endocrinol. 167(2), 235-244 (2012). https://doi.org/10.1530/eje12-0147

20. M.V. Davi, L. Dalle Carbonare, A. Giustina, M. Ferrari, A. Frigo, V. Lo Cascio, G. Francia, Sleep apnoea syndrome is highly prevalent in acromegaly and only partially reversible after 
biochemical control of the disease. Eur. J. Endocrinol. 159(5), 533-540 (2008). https://doi.org/10.1530/eje-08-0442

21. M. Bex, R. Abs, G. T. Sjoen, J. Mockel, B. Velkeniers, K. Muermans, D. Maiter, AcroBel-the Belgian registry on acromegaly: a survey of the 'real-life' outcome in 418 acromegalic subjects. Eur. J. Endocrinol. 157(4), 399-409 (2007). https://doi. org/10.1530/eje-07-0358

22. T. Brue, F. Castinetti, F. Lundgren, M. Koltowska-Haggstrom, P. Petrossians, Which patients with acromegaly are treated with pegvisomant? An overview of methodology and baseline data in ACROSTUDY. Eur. J. Endocrinol. 161, (Suppl 1), 11-S17 (2009). https://doi.org/10.1530/eje-09-0333

23. A. Colao, R.S. Auriemma, M. Galdiero, G. Lombardi, R. Pivonello, Effects of initial therapy for five years with somatostatin analogs for acromegaly on growth hormone and insulin-like growth factor-I levels, tumor shrinkage, and cardiovascular disease: a prospective study. J. Clin. Endocrinol. Metab. 94(10), 3746-3756 (2009). https://doi.org/10.1210/jc.2009-0941

24. A. Colao, R. Pivonello, L.F. Grasso, R.S. Auriemma, M. Galdiero, S. Savastano, G. Lombardi, Determinants of cardiac disease in newly diagnosed patients with acromegaly: results of a 10 year survey study. Eur. J. Endocrinol. 165(5), 713-721 (2011). https:// doi.org/10.1530/eje-11-0408

25. A. Colao, Improvement of cardiac parameters in patients with acromegaly treated with medical therapies. Pituitary 15(1), 50-58 (2012). https://doi.org/10.1007/s11102-011-0318-z

26. R.S. Auriemma, L.F. Grasso, M. Galdiero, M. Galderisi, C. Pivonello, C. Simeoli, M.C. De Martino, R. Ferrigno, M. Negri, C. de Angelis, R. Pivonello, A. Colao, Effects of long-term combined treatment with somatostatin analogues and pegvisomant on cardiac structure and performance in acromegaly. Endocrine $\mathbf{5 5}$ (3), 872-884 (2017). https://doi.org/10.1007/s12020-016-0995-5

27. M. Sherlock, R.C. Reulen, A. Aragon-Alonso, J. Ayuk, R.N. Clayton, M.C. Sheppard, M.M. Hawkins, A.S. Bates, P.M. Stewart, A paradigm shift in the monitoring of patients with acromegaly: last available growth hormone may overestimate risk. J. Clin. Endocrinol. Metab. 99(2), 478-485 (2014). https://doi.org/ 10.1210/jc.2013-2450

28. J.D. Carmichael, M.S. Broder, D. Cherepanov, E. Chang, A. Mamelak, Q. Said, M.P. Neary, V. Bonert, The association between biochemical control and cardiovascular risk factors in acromegaly. BMC Endocr. Disord. 17(1), 15 (2017). https://doi. org/10.1186/s12902-017-0166-6

29. L.A. Portocarrero-Ortiz, A. Vergara-Lopez, M. Vidrio-Velazquez, A.M. Uribe-Diaz, A. Garcia-Dominguez, A.A. Reza-Albarran, D. Cuevas-Ramos, V. Melgar, J. Talavera, A.J. Rivera-Hernandez, C. V. Valencia-Mendez, M. Mercado, The Mexican Acromegaly Registry: clinical and biochemical characteristics at diagnosis and therapeutic outcomes. J. Clin. Endocrinol. Metab. 101(11), 3997-4004 (2016). https://doi.org/10.1210/jc.2016-1937

30. A. Mestron, S.M. Webb, R. Astorga, P. Benito, M. Catala, S. Gaztambide, J.M. Gomez, I. Halperin, T. Lucas-Morante, B. Moreno, G. Obiols, P. de Pablos, C. Paramo, A. Pico, E. Torres, C. Varela, J.A. Vazquez, J. Zamora, M. Albareda, M. Gilabert, Epidemiology, clinical characteristics, outcome, morbidity and mortality in acromegaly based on the Spanish Acromegaly Registry (Registro Espanol de Acromegalia, REA). Eur. J. Endocrinol. 151(4), 439-446 (2004)

31. X. Guo, L. Gao, S. Zhang, Y. Li, Y. Wu, L. Fang, K. Deng, Y. Yao, W. Lian, R. Wang, B. Xing, Cardiovascular system changes and related risk factors in acromegaly patients: a case-control study. Int J. Endocrinol. 2015, 573643 (2015). https://doi.org/10. 1155/2015/573643. doi: 573610.571155/572015/573643

32. C.M. dos Santos Silva, I. Gottlieb, I. Volschan, L. Kasuki, L. Warszawski, G.A. Balarini Lima, S.S. Xavier, R.C. Pedrosa, L.V. Neto, M.R. Gadelha, Low frequency of cardiomyopathy using cardiac magnetic resonance imaging in an acromegaly contemporary cohort. J. Clin. Endocrinol. Metab. 100(12), 4447-4455 (2015). https://doi.org/10.1210/jc.2015-2675

33. A.S. Powlson, M. Gurnell, Cardiovascular disease and sleepdisordered breathing in acromegaly. Neuroendocrinology 103(1), 75-85 (2016). https://doi.org/10.1159/000438903

34. P. Attal, P. Chanson, Endocrine aspects of obstructive sleep apnea. J. Clin. Endocrinol. Metab. 95(2), 483-495 (2010). https:// doi.org/10.1210/jc.2009-1912

35. L.M. Galerneau, J.L. Pepin, A.L. Borel, O. Chabre, M. Sapene, B. Stach, J. Girey-Rannaud, N. Arnol, R. Tamisier, P. Caron, Acromegaly in sleep apnoea patients: a large observational study of 755 patients. Eur. Respir. J. 48(5), 1489-1492 (2016). https:// doi.org/10.1183/13993003.01229-2016

36. S. Fieffe, I. Morange, P. Petrossians, P. Chanson, V. Rohmer, C. Cortet, F. Borson-Chazot, T. Brue, B. Delemer, Diabetes in acromegaly, prevalence, risk factors, and evolution: data from the French Acromegaly Registry. Eur. J. Endocrinol. 164(6), 877-884 (2011). https://doi.org/10.1530/eje-10-1050

37. C. Jonas, D. Maiter, O. Alexopoulou, Evolution of glucose tolerance after treatment of acromegaly: a study in 57 patients. Horm. Metab. Res 48(5), 299-305 (2016). https://doi.org/10. 1055/s-0035-1569277

38. C. Wen-Ko, C. Szu-Tah, L. Feng-Hsuan, C. Chen-Nen, W. MingHsu, L. Jen-Der, The impact of diabetes mellitus on the survival of patients with acromegaly. Endokrynol. Pol. 67(5), 501-506 (2016). https://doi.org/10.5603/EP.a2016.0031

39. G. Mazziotti, I. Floriani, S. Bonadonna, V. Torri, P. Chanson, A. Giustina, Effects of somatostatin analogs on glucose homeostasis: a meta analysis of acromegaly studies. J. Clin. Endocrinol. Metab. 94(5), 1500-1508 (2009). https://doi.org/10.1210/jc.2008-2332

40. C. Urbani, C. Sardella, A. Calevro, G. Rossi, I. Scattina, M Lombardi, I. Lupi, L. Manetti, E. Martino, F. Bogazzi, Effects of medical therapies for acromegaly on glucose metabolism. Eur. J. Endocrinol. 169(1), 99-108 (2013). https://doi.org/10.1530/eje13-0032

41. P.J. Caron, J.S. Bevan, S. Petersenn, D. Flanagan, A. Tabarin, G. Prévost, P. Maisonobe, A. Clermont, Tumor shrinkage with lanreotide autogel $120 \mathrm{mg}$ as primary therapy in acromegaly: results of a prospective multicenter clinical trial. J. Clin. Endocrinol. Metab. 99(4), 1282-1290 (2014). https://doi.org/10.1210/jc.20133318

42. P.J. Caron, S. Petersenn, A. Houchard, C. Sert, J.S. Bevan, Glucose and lipid levels with lanreotide autogel $120 \mathrm{mg}$ in treatmentnaive patients with acromegaly: data from the PRIMARYS study. Clin. Endocrinol. (Oxf.) 86(4), 541-551 (2017). https://doi.org/10. 1111/cen.13285

43. H.A. Schmid, T. Brue, A. Colao, M.R. Gadelha, I. Shimon, K. Kapur, A.M. Pedroncelli, M. Fleseriu, Effect of pasireotide on glucose- and growth hormone-related biomarkers in patients with inadequately controlled acromegaly. Endocrine 53, 210-219 (2016). https://doi.org/10.1007/s12020-016-0895-8

44. K.C. Leung, N. Doyle, M. Ballesteros, M.J. Waters, K.K. Ho, Insulin regulation of human hepatic growth hormone receptors: divergent effects on biosynthesis and surface translocation. J. Clin. Endocrinol. Metab. 85(12), 4712-4720 (2000). https://doi.org/10. 1210/jcem.85.12.7017

45. A. Ciresi, M.C. Amato, R. Pivonello, E. Nazzari, L.F. Grasso, F. Minuto, D. Ferone, A. Colao, C. Giordano, The metabolic profile in active acromegaly is gender-specific. J. Clin. Endocrinol. Metab. 98(1), E51-E59 (2013). https://doi.org/10.1210/jc.20122896

46. H.K. Gleeson, C.A. Lissett, S.M. Shalet, Insulin-like growth factor-I response to a single bolus of growth hormone is increased in obesity. J. Clin. Endocrinol. Metab. 90(2), 1061-1067 (2005). https://doi.org/10.1210/jc.2004-0501 
47. S.Y. Nam, E.J. Lee, K.R. Kim, H.C. Lee, M.S. Nam, J.H. Cho, K. B. Huh, Long-term administration of acipimox potentiates growth hormone response to growth hormone-releasing hormone by decreasing serum free fatty acid in obesity. Metabolism 45(5), 594-597 (1996). https://doi.org/10.1016/S0026-0495(96)90029-3

48. M. Matta, V. Bongard, S. Grunenwald, J.-C. Maiza, A. Bennet, P. Caron, Clinical and metabolic characteristics of acromegalic patients with high IGF1/normal GH levels during somatostatin analog treatment. Eur. J. Endocrinol. 164(6), 885-889 (2011). https://doi.org/10.1530/eje-11-0098

49. T. Rokkas, D. Pistiolas, P. Sechopoulos, G. Margantinis, G. Koukoulis, Risk of colorectal neoplasm in patients with acromegaly: A meta-analysis. World J. Gastroenterol. 14(22), 3484-3489 (2008). https://doi.org/10.3748/wjg.14.3484

50. A.G. Renehan, J. O'Connell, D. O'Halloran, F. Shanahan, C.S. Potten, S.T. O'Dwyer, S.M. Shalet, Acromegaly and colorectal cancer: a comprehensive review of epidemiology, biological mechanisms, and clinical implications. Horm. Metab. Res. 35(1112), 712-725 (2003). https://doi.org/10.1055/s-2004-814150

51. O. Manousos, J. Souglakos, C. Bosetti, A. Tzonou, V. Chatzidakis, D. Trichopoulos, H.O. Adami, C. Mantzoros, IGF-I and IGF-II in relation to colorectal cancer. Int. J. Cancer 83(1), 15-17 (1999)

52. P.J. Jenkins, P.D. Fairclough, Screening guidelines for colorectal cancer and polyps in patients with acromegaly. Gut 51(suppl 5), v13-v14 (2002). https://doi.org/10.1136/gut.51.suppl_5.v13

53. D. Dworakowska, M. Gueorguiev, P. Kelly, J.P. Monson, G.M. Besser, S.L. Chew, S.A. Akker, W.M. Drake, P.D. Fairclough, A. B. Grossman, P.J. Jenkins, Repeated colonoscopic screening of patients with acromegaly: 15-year experience identifies those at risk of new colonic neoplasia and allows for effective screening guidelines. Eur. J. Endocrinol. 163(1), 21-28 (2010). https://doi. org/10.1530/eje-09-1080

54. M.B. Gordon, S. Nakhle, W.H. Ludlam, Patients with acromegaly presenting with colon cancer: a case series.Case Rep. Endocrinol. 2016, 4 (2016). https://doi.org/10.1155/2016/5156295

55. P. Agarwal, P. Rai, M. Jain, S. Mishra, U. Singh, S.K. Gupta, Prevalence of colonic polyp and its predictors in patients with acromegaly. Indian J. Endocrinol. Metab. 20(4), 437-442 (2016). https://doi.org/10.4103/2230-8210.183455

56. S. Petersenn, M. Buchfelder, B. Gerbert, H. Franz, H.J. Quabbe, H.M. Schulte, M. Grussendorf, M. Reincke, Age and sex as predictors of biochemical activity in acromegaly: analysis of 1485 patients from the German Acromegaly Register. Clin. Endocrinol. (Oxf.) 71(3), 400-405 (2009). https://doi.org/10.1111/j.13652265.2009.03547.x

57. M. Sherlock, R.C. Reulen, A.A. Alonso, J. Ayuk, R.N. Clayton, M.C. Sheppard, M.M. Hawkins, A.S. Bates, P.M. Stewart, ACTH deficiency, higher doses of hydrocortisone replacement, and radiotherapy are independent predictors of mortality in patients with acromegaly. J. Clin. Endocrinol. Metab. 94(11), 4216-4223 (2009). https://doi.org/10.1210/jc.2009-1097

58. A.K. Annamalai, E.L. Gayton, A. Webb, D.J. Halsall, C. Rice, F. Ibram, A.N. Chaudhry, H.L. Simpson, L. Berman, M. Gurnell, Increased prevalence of gallbladder polyps in acromegaly. J. Clin. Endocrinol. Metab. 96(7), E1120-E1125 (2011). https://doi.org/ $10.1210 /$ jc. $2010-2669$ 